\title{
Characterization of the Kentville Stock Clone Apple Rootstocks. I. Growth and Efficiency
}

\author{
C.G. Embree' ${ }^{1}$ B.H. Lesser ${ }^{2}$, and A.D. Crowe ${ }^{3}$ \\ Research Station, Agriculture Canada, Kentville, N.S., B4N 1J5, Canada
}

\begin{abstract}
Additional index words. Malus domestica, rootstocks, hardiness, growth, efficiency
Abstract. The 30 apple (Malus domestica Borkh.) rootstock candidates selected for cold hardiness, known as the Kentville Stock Clone (KSC), with 'McIntosh' and 'Delicious' as scion cultivars, were compared at 11 years of age for tree size, weight, fruit yield, and crop efficiency under field conditions. Trunk cross-section area and tree weight were highly correlated. Tree size was similar for the two cultivars in most cases and ranged in size from semidwarf to very vigorous. Cumulative yield efficiencies varied by nearly two-fold and were not correlated with tree size. The most efficient rootstocks were KSC 28 , KSC 7, and KSC 6 in the semidwarf, semivigorous, and vigorous size classifications, respectively.
\end{abstract}

The need for size-controlling apple rootstocks that are well adapted to North American conditions climaxed when Cummins and Aldwinckle (1974) targeted the three most widely planted (Zeiger and Tukey, 1960) East Malling selections-M.9, M.26, and MM.106-for replacement through their breeding program. Failure of these and other selections in some sites and inconsistent performance across the apple production regions was the underlying motivation for rootstock research in Canada (Hutchinson, 1975) and for internationally coordinated field trials (Ferree and Perry, 1988). Further evidence of the need to find rootstocks fully adapted to the conditions of specific apple production regions is the number of apple rootstock improvement programs that exist around the world (Cummins and Aldwinkle, 1983). The discovery of rootstocks with a range of vigor and potential hardiness is, therefore, worthy of further evaluation. This opportunity arose in Eastern Canada with the development of the winter hardy KSC apple rootstocks (Embree and Crowe, 1986). The next phase in rootstock evaluation should include field performance with at least one cultivar (Barritt et al., 1990; Cummins and Aldwinckle, 1988).

Preliminary findings of field performance with two cultivars were previously reported (Embree, 1989). The results of further and more detailed rootstock characterization are presented here in a series of three papers. The first paper documents the effects of the KSC rootstocks with 'McIntosh' and 'Delicious' on tree size, weight, and yield efficiency. The second paper analyzes and compares the precocity and productivity of these rootstocks, and the third deals with effects of the rootstocks on quality of fruit produced and summarizes results highlighting superior performers .

\section{Materials and Methods}

The KSC apple rootstocks were selected from 'Beautiful Arcade' seedlings with common Antonovka as the primary pollen source. The hardiness selection was made following severe winter

Received for publication 6 Jan. 1992. Accepted for publication 25 Aug. 1992. Kentville Station Publication no. 2096. We wish to thank D. Crouse and D. Baldwin for technical support, K. McRae for assistance with statistical analysis, and J. Wilson for the original selection of the rootstock survivors. The cost of publishing this paper was defrayed in part by the payment of page charges. Under postal regulations, this paper therefore must be hereby marked advertisement solely to indicate this fact.

${ }^{1}$ Research Scientist.

${ }^{2}$ Research Scientist, term appointment.

${ }^{3}$ Research Scientist, retired. damage in a nursery, where only 30 of 9000 seedlings survived a particularly harsh winter (Embree and Crowe, 1986).

In Spring 1978, 'Blackmac McIntosh' and 'Starking Red Delicious' trees propagated on the $30 \mathrm{KSC}$ rootstocks were planted as 1-year whips in a complete-block design with five single-tree replications spaced at $4.3 \times 6.1 \mathrm{~m}$ (383 trees/ha), randomized for rootstock but not for cultivar. Fruit yield, trunk girth [recorded as trunk cross-sectional area (TCA)], and weight of prunings were recorded annually. In 1988, trees in the vigorous group had filled their allotted space and required containment pruning to hold at this spacing. The trial was terminated in Nov. 1988 and all trees were cut at $15 \mathrm{~cm}$ above the ground and weighed.

Efficiency, expressed as total yield relative to tree size, was determined. Comparison of efficiencies is affected by yearly fluctuations in yield. Therefore, to avoid biennial effects on efficiency calculations, straight lines were fitted to plots of yearly efficiencies (cumulative yield at the end of each year divided by TCA in that year) against tree age. The regression accounted for $95 \%$ to $98 \%$ of the variability in the data. Each rootstock was characterized by the X-intercept, which corresponds to time of first production, and the slope, which corresponds to the rate of increase in efficiency. From these parameters, cumulative efficiency for any given year can be calculated.

\section{Results and Discussion}

Tree size. The most dwarfing rootstocks were KSC 28, 14, 26, 18, and 23, while the most vigorous were KSC 2, 5, and 6 (Fig.1). For the KSC rootstocks at 11 years of age, there was a range in TCA of 122 to $233 \mathrm{~cm}^{2}$ (1.9-fold) for 'McIntosh' and 136 to $254 \mathrm{~cm}^{2}$ (1.9-fold) for 'Delicious'. In comparison, in a 14-year trial in Poland, tree sizes on a variety of rootstocks (M.9 to A.2) varied from 151 to $292 \mathrm{~cm}^{2}$ (1.9-fold), 122 to $236 \mathrm{~cm}^{2}$ (1.9-fold), and 148 to $252 \mathrm{~cm}^{2}$ (1.7-fold) with 'McIntosh', 'Cortland', and 'Delicious,' respectively, as scion cultivars (Czynczyk and Olszewska 1990). Vigor in that series ranged from dwarf to semivigorous. It is apparent that the KSC rootstocks displayed a similarly wide range of tree vigor.

Tree size was expressed in terms of TCA, aboveground weight at time of removal, and total weight (including accumulated prunings) (Fig. 2). There was excellent correlation among the three methods of measuring tree size. For TCA, the coefficient of variation with tree weight and total weight was $7.6 \%$ and $7.5 \%$,

Abbreviations: KSC, Kentville Stock Clone: TCA, trunk cross-sectional area. 


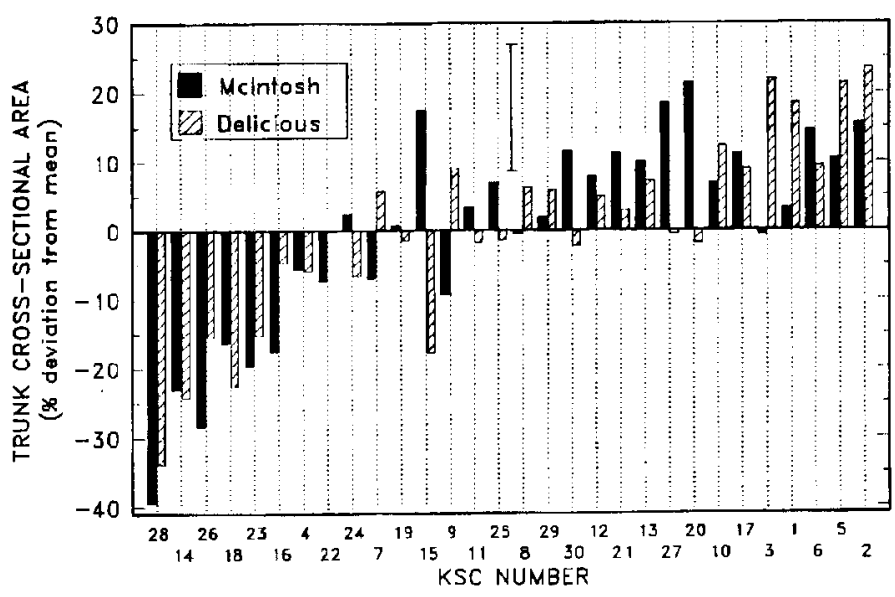

Fig. 1. Relative size of 'McIntosh' and 'Delicious' scions on the $30 \mathrm{KSC}$ rootstocks expressed as percent deviation of TCA for each cultivar/rootstock combination from the mean TCA for that cultivar on all rootstocks, in order of increasing average TCA for both cultivars on each rootstock. The error bar indicates the least significant difference at $P=0.05$.

respectively. This result supports earlier work by Westwood and Roberts (1970) who, with six cultivars and seven rootstocks, found a linear relationship between trunk TCA and the fresh weight of the tree. This relationship is likely to continue until pruning and or crowding restricts canopy expansion.

While relative tree size on the same stock clone varied somewhat between the two cultivars, in general, they followed the same trend from most dwarfing to most vigorous. The most extreme exception was KSC 15, where TCA for 'McIntosh' was $42 \%$ larger than for 'Delicious'. For four others (KSC 20, 3, 9, and 27) the difference in TCA between the two cultivars was also significant ( $\mathrm{P}<0.05)$. 'McIntosh' was larger on KSC 20 and 27, while 'Delicious' was larger on KSC 3 and 9. Because our trial was not randomized for cultivar, however, it is not clear if there was an interaction between scion cultivars and rootstock clones for tree size. Czynczyk and Olszewska (1990) did not observe such an interaction. In all cases of which we are aware, where significant scion/stock interactions were reported, the effects were noted during the onset phase of cropping and not after full production had been reached. This relationship is discussed in more detail in Lesser et al. (1993).

Yield efficiency. Because of the high correlation between TCA and weight of wood produced (Fig. 2), it would be expected that efficiency could be expressed either in terms of fruit yield relative to TCA or relative to weight of wood. The correlation coefficient for the two methods of expressing efficiency was 0.89 .

There was no trend with tree size for any of the calculated yield efficiency characteristics: time of first production, rate of increase in efficiency, or cumulative efficiency at year 11 (Table 1). After 11 years, yield efficiency varied from 3.16 to $5.63 \mathrm{~kg} \cdot \mathrm{cm}^{-2}$ (1.8-fold) for 'McIntosh' and from 2.07 to $3.97 \mathrm{~kg} \cdot \mathrm{cm}^{-2}$ (1.9-fold) for 'Delicious'. Among the more dwarfing stocks, the most efficient was KSC 28 for both cultivars. Among the semivigorous stocks, KSC 16, 7, and 11 showed high efficiencies, and among the vigorous stocks, KSC 6 and 13 were the most efficient. KSC 19, 30, 27, and 20 showed the lowest efficiencies with both cultivars. Certain rootstocks were inconsistent with the two cultivars, e.g., KSC 24 was much more efficient relative to the mean efficiency for all rootstocks with 'Delicious' than with 'McIntosh', while for KSC 1 and KSC 3, the reverse was true. The value of using more than one scion cultivar when screening new rootstock introductions, despite the added expense, is demonstrated effectively by these observations.

When comparing the two cultivars, 'McIntosh' was 55\% more efficient than 'Delicious'. This result was due to differences in precocity and in productivity (Lesser et al., 1993). On the same stock, the average efficiency of 'McIntosh' was higher than that of 'Delicious' by 50\% in Poland (Czynczyk and Olszewska, 1990) and by $22 \%$ in Michigan (Dennis, 1979). Preliminary results from a British Columbia trial, however, showed 'McIntosh' to be less
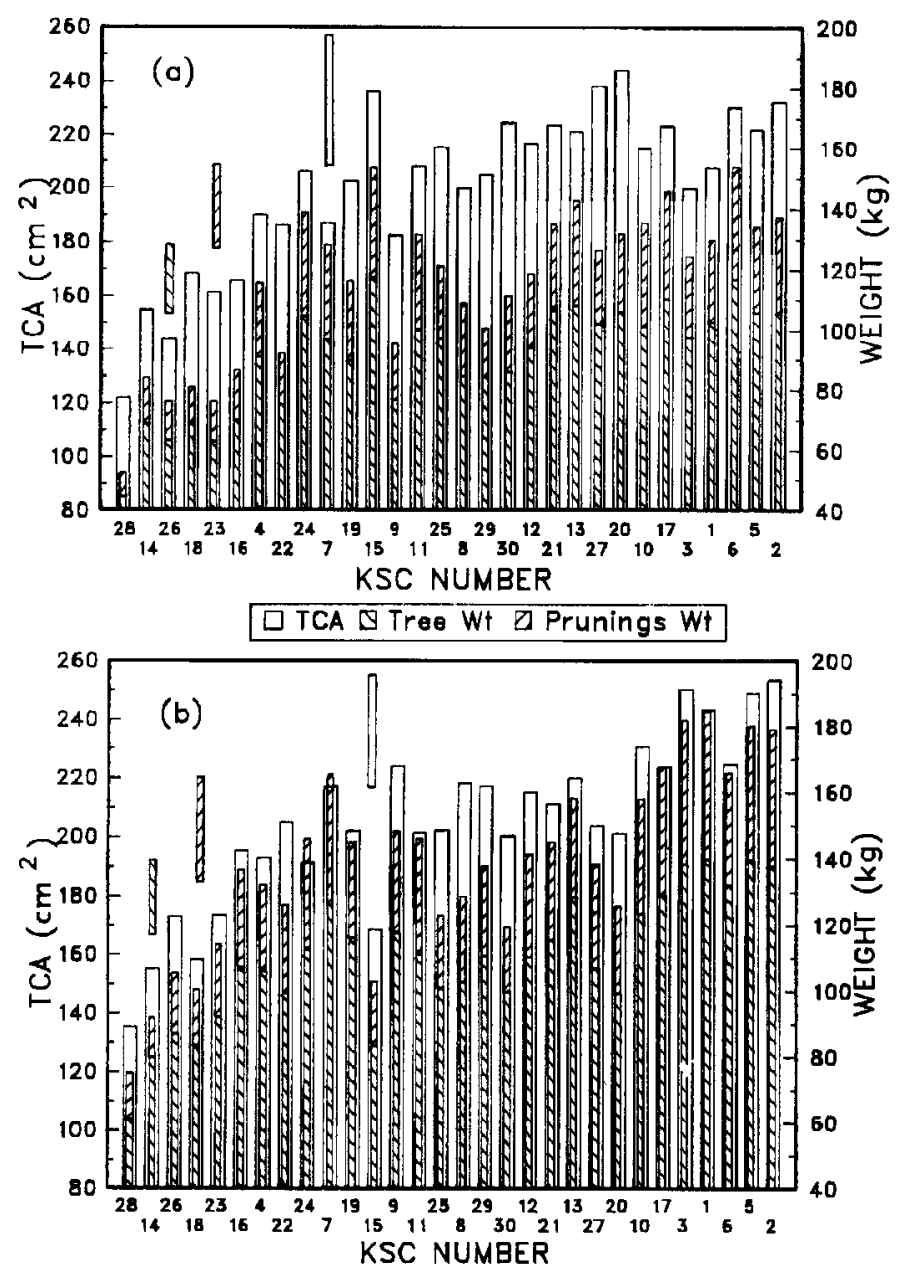

Fig. 2. TCA, tree weight at time of removal, and weight of prunings for (a) 'McIntosh' and (b) 'Delicious' on the $30 \mathrm{KSC}$ rootstocks, in order of increasing average TCA. The error bars indicate the least significant different at $P=0.05$ for TCA, tree weight, and total weight (tree weight + prunings).

than half as efficient as 'Delicious' (Fitzpatrick and Emmond, 1990).

The projected yield per hectare for the most efficient of the KSC rootstocks, based on 1988 yields and tree densities proportional to the dwarfing effect of the rootstock (383/ha for an average size tree), was $100.4 \mathrm{t} \cdot \mathrm{ha}^{-1}$ for 'McIntosh' and $81.5 \mathrm{t} \cdot \mathrm{ha}^{-1}$ for 'Delicious'. These are very high yields for any modem apple production system at 11 years. This result alone supports development of the best of the KSC rootstocks and justifies further study of the underlying cause. 
Table 1. Regression of efficiency on years after planting for each apple cultivar/KSC rootstock combination in order of increasing average tree size.

\begin{tabular}{|c|c|c|c|c|c|c|}
\hline \multirow[b]{2}{*}{$\begin{array}{l}\mathrm{KSC} \\
\text { (no) }\end{array}$} & \multicolumn{3}{|c|}{ McIntosh } & \multicolumn{3}{|c|}{ Delicious } \\
\hline & $\begin{array}{l}\text { Time of first } \\
\text { production } \\
(\mathrm{yr})\end{array}$ & $\begin{array}{c}\text { Increase in } \\
\text { efficiency } \\
\left(\mathrm{kg} \cdot \mathrm{cm}^{-2} \cdot \mathrm{yr}^{-1}\right)\end{array}$ & $\begin{array}{c}\text { Efficiency at } \\
\text { year } 11 \\
\left(\mathrm{~kg} \cdot \mathrm{cm}^{-2}\right)\end{array}$ & $\begin{array}{l}\text { Time of first } \\
\text { production } \\
(\mathrm{yr})\end{array}$ & $\begin{array}{c}\text { Increase in } \\
\text { efficiency } \\
\left(\mathrm{kg} \cdot \mathrm{cm}^{-2} \cdot \mathrm{yr}^{-1}\right)\end{array}$ & $\begin{array}{c}\text { Cumulative efficiency } \\
\text { at year } 11 \\
\left(\mathrm{~kg} \cdot \mathrm{cm}^{-2}\right)\end{array}$ \\
\hline 28 & 3.27 & 0.60 & 4.68 & 3.73 & 0.50 & 3.62 \\
\hline 14 & 4.44 & 0.60 & 3.92 & 4.77 & 0.36 & 2.29 \\
\hline 26 & 4.04 & 0.59 & 4.09 & 4.26 & 0.37 & 2.51 \\
\hline 18 & 3.64 & 0.62 & 4.54 & 4.39 & 0.49 & 3.21 \\
\hline 23 & 4.08 & 0.62 & 4.31 & 4.30 & 0.40 & 2.68 \\
\hline 16 & 3.94 & 0.65 & 4.59 & 4.47 & 0.49 & 3.21 \\
\hline 4 & 3.74 & 0.63 & 4.55 & 4.36 & 0.41 & 2.76 \\
\hline 22 & 3.82 & 0.59 & 4.26 & 4.56 & 0.38 & 2.45 \\
\hline 24 & 3.59 & 0.64 & 4.70 & 4.12 & 0.57 & 3.91 \\
\hline 7 & 3.36 & 0.74 & 5.63 & 4.25 & 0.49 & 3.29 \\
\hline 19 & 4.16 & 0.54 & 3.68 & 4.52 & 0.36 & 2.33 \\
\hline 15 & 3.61 & 0.66 & 4.85 & 4.15 & 0.43 & 2.91 \\
\hline 9 & 4.34 & 0.60 & 4.00 & 4.39 & 0.38 & 2.52 \\
\hline 11 & 3.24 & 0.59 & 4.56 & 4.12 & 0.54 & 3.73 \\
\hline 25 & 3.36 & 0.58 & 4.42 & 4.05 & 0.38 & 2.68 \\
\hline 8 & 4.00 & 0.55 & 3.87 & 4.24 & 0.37 & 2.48 \\
\hline 29 & 4.04 & 0.57 & 4.00 & 4.56 & 0.33 & 2.12 \\
\hline 30 & 3.24 & 0.44 & 3.39 & 4.28 & 0.38 & 2.55 \\
\hline 12 & 3.64 & 0.60 & 4.37 & 4.32 & 0.45 & 2.99 \\
\hline 21 & 3.82 & 0.62 & 4.44 & 4.16 & 0.39 & 2.65 \\
\hline 13 & 3.84 & 0.64 & 4.58 & 4.32 & 0.45 & 3.03 \\
\hline 27 & 3.84 & 0.56 & 4.01 & 4.47 & 0.32 & 2.09 \\
\hline 20 & 4.07 & 0.56 & 3.88 & 4.68 & 0.35 & 2.21 \\
\hline 10 & 3.54 & 0.57 & 4.25 & 4.49 & 0.39 & 2.52 \\
\hline 17 & 3.77 & 0.62 & 4.48 & 4.16 & 0.42 & 2.90 \\
\hline 3 & 3.32 & 0.67 & 5.16 & 4.22 & 0.40 & 2.69 \\
\hline 1 & 3.75 & 0.61 & 4.44 & 4.58 & 0.39 & 2.54 \\
\hline 6 & 3.62 & 0.71 & 5.27 & 4.37 & 0.49 & 3.28 \\
\hline 5 & 3.45 & 0.57 & 4.29 & 4.52 & 0.42 & 2.73 \\
\hline 2 & 4.00 & 0.56 & 3.94 & 4.45 & 0.36 & 2.38 \\
\hline Mean & 3.75 & 0.60 & 4.33 & 4.34 & 0.42 & 2.78 \\
\hline SEM & 0.185 & 0.029 & 0.220 & 0.128 & 0.026 & 0.194 \\
\hline
\end{tabular}

\section{Literature Cited}

Barritt, B.H., M.A. Dilley, and B.J. Schonburg. 1990. Potentialnew apple rootstocks producing trees similar to M. 9 in size. Compact Fruit Tree. 26:4-7.

Cummins, J.N. and H.S. Aldwinckle. 1974. Breeding apple rootstocks. HortScience 9:367-372.

Cummins, J.N. and H.S. Aldwinckle. 1983. Breeding apple rootstocks, p. 294-394. In: J. Janick (ed.). Plant breeding reviews, AVI Publ., Westport, Conn.

Cummins, J.N. and H.S. Aldwinckle. 1988. New directions in rootstock breeding: Introduction to the symposium, p. 100-101. Proc. Rootstock Breeding and Evaluation. Symp. HortScience 23.

Czynczyk, A. and B. Olszewska. 1990. Growth and yielding of 3 apple cultivars on rootstocks of Polish and foreign origin. Fruit Sci. Rpt. 17(2):65-75.

Dennis, F.G. 1979. Factors affecting yield in apple, with emphasis on 'Delicious'. Hort. Rev. 1:395-422.

Embree, C.G. 1989. Yield, vigor and efficiency of 10 year old 'McIntosh' and 'Red Delicious' on $30 \mathrm{KSC}$ apple rootstocks compared to former trials with M.7 and MM.106. Acta Hort. 243:83-86.

Embree, C.G. and A.D. Crowe. 1986. The origin and development of the KSC apple rootstocks. Fruit Var. J. 40:116-120.

Ferree, D.C. and R.L. Perry. 1988. Rootstock evaluation through the NC-140 project. HortScience 23: 102-104.

Fitzpatrick, J. and S. Emmond. 1990. B.C. Fruit growers' test orchard limited. Compact Fruit Tree 23:147-149.

Hutchinson, A. 1975. Historical sketch of pome fruit rootstock work in Canada. Fruit Var. J. 29:38-41.

Lesser, B.H., C.G. Embree, and A.D. Crowe. 1992. Characterization of the Kentville Stock Clone apple rootstocks. II. Precocity and productivity. J. Amer. Soc. Hort. Sci. 118:173-176.

Westwood, M.N. and A.N. Roberts. 1970. Therelationship betweentrunk cross-sectional area and the weight of apple trees. J. Amer. Soc. Hort. Sci. 95:28-30.

Zeiger, D. and H.B. Tukey. 1960. An historical review of the 'Malling' apple rootstocks in America. Michigan State Univ. Circ. Bul. 226. 